\title{
Enterprise Integration Modeling for Extended Enterprise in ERP Systems
}

\author{
Luciana Rocha dos Santos ${ }^{1}$, Simone Vasconcelos Silva ${ }^{2}$ and Renato de Campos ${ }^{3}$ \\ ${ }^{1}$ Estácio de Sá University, Avenida 28 de Março, 423 - Centro - Campos dos Goytacazes - \\ Brazil www.estacio.br lurochas@yahoo.com.br \\ ${ }^{2}$ Federal Center for Technological Education of Campos, Rua Dr. Siqueira, 273 - Parque \\ Dom Bosco - Campos dos Goytacazes - Brazil simonevs@cefetcampos.br \\ ${ }^{3}$ São Paulo State University, Av. Eng. Edmundo Carrijo Coube, no 14-01 - Bauru - Brazil \\ rcampos@feb.unesp.br
}

\begin{abstract}
Currently, the companies overcome its organization barriers stimulated by the necessity of market expansion, minimize the enterprise costs, search for competitive advantages and need to absorb the fast market changes. New forms of organizations arise and are called extended and agile enterprises with new factors to be observed in the implementation of the integrated systems such as enterprise resources planning (ERP). Defining business processes of these organizations turn the task of modeling of the system integrated information sufficiently complex. In order to control all these variables of the businesses world and minimize the effect of the high risk of investment, it is necessary to use adequate methodologies. This article presents the main difficulties in the implantation of ERP systems and proposes a modeling methodology for networking enterprise with CIMOSA and UML.
\end{abstract}

Keywords: Business process modeling. Enterprise agility, Extended enterprise, Enterprise resource panning (ERP), UML, CIMOSA.

\section{INTRODUCTION}

Large organizations have invested greatly on complex systems, such as: ERP (Enterprise Resource Planning). With globalization, the systems need to adapt themselves to the constant changes and environments that extend the is organizational barriers with new business partners. New organizational paradigms are established such as: the Agile Enterprise and the Extended Enterprise.

Trends of the industries would be characterized by: globalization, parallelization, agility, virtual company, customer's satisfaction and quality. In this perspective, the challenge is to integrate and coordinate the business processes efficiently, in an interorganizational environment and in continuous changing, and for that is necessary to model and plan the enterprise [1].

This article makes one brief description of organizational paradigms, ERP systems, business process, enterprise modeling and proposes to integrate the best business modeling practical as: CIMOSA and UML. The next section detaches the organizational paradigms as: Agile enterprise and Extended enterprise. In section 3 it 
is done an explanation regarding ERP systems showing, difficulties and perspectives. Section 4 shows the necessity of the business process modeling. Section 5 presents the enterprise modeling using CIMOSA and UML. In section 6 it is presented a proposal to the modeling of ERP systems, based on the development processes CIMOSA and UML; and in the section there are the 7 final considerations.

\section{ORGANIZATIONAL PARADIGMS}

The enterprises are live things. They constantly need to be redesigned to adjust themselves with the necessary agility to the alignment of new technologies, and to guarantee intra and inter-organizational improvements. The challenges faced by the enterprises in more dynamic and competitive markets take the definition of organizational paradigms as Agile enterprise and Extended enterprise [2-3].

The agile enterprise is the ability of an organization to detect the environment change and to answer efficiently and effectively to these changes, and thus to compete successfully in an of uncertain and unexpected business environment. The agility requires the integration of some factors: flexible production technologies, a competent work force, knowledge, and management of organizational structures that promote and stimulate cooperative initiatives between the enterprises [4-5].

The context of an Extended Enterprise represents the organizations in which "the main" enterprise, that is, dominant, "extends" its limits to suppliers or business partners, based mainly on contracts that establish rules for the collaboration net, however, an existing difficulty is the information exchange and knowledge among the collaboration of net partners, that is, to follow the production process or entire service, inside the organization until the associated organization or extended [6].

\section{ERP SYSTEMS}

The ERP is standardized software designed to integrate the internal value chain of an enterprise, based on an integrated database and consists on diverse modules aiming specific business functions [7].

Currently, to wait on the enterprise demands, it is verified a strong trend in the use of free software, which possesses advantages as reduction of costs and differentiated technical characteristics [3]. The ERP5 proposal is innovative because it uses object oriented database technology, it combines ERP and content management, and it is projected to be distributed with specific characteristics. Multilingual it deals with several currencies. Multi-user, it allows several enterprises. Meta-ERP in MetaPlanning manages a group of companies that belong to the same holding or manages an abstract organization. Synchronization, it is projected to be implemented in several places through the Internet and has characteristics of EDI (Electronic Data Interchange) standard [8].

To implant an ERP system can be a difficult and risky process. Typically, it has an impact on the entire organization, and generally, it is associated to the reengineering 
of business process, being necessary a strong management and control of the organizational changes. Some elements of risk threaten the success of ERP projects, and when the risks are not immediately detected and corrected, each subsequent phase inherits the problems not resolved. The implantation of the ERP requires abilities such as: change management, risk management, business process reengineering, beyond technical knowledge of execution [9-10].

\section{BUSINESS PROCESS MODELING}

In complex systems, business processes, components and then interactions they are in constant changing, so, it is not possible to establish them definitive by. The business processes integration and the information technology has been one of the key factors for a successful execution of an integrated enterprise system [11].

With the reference models, the modifications of alignment lessen their costs, time and complexity. The business processes modeling is essential to adjust the gaps between ERP system and the business model of the enterprise. The future of the ERP is to integrate the diverse aspects that compose ERP system with the external environment [1].

\section{ENTERPRISE MODELING USING CIMOSA AND UML}

Modeling the enterprise is an essential pre-requirement to capture the variables of the businesses world and to get an approach of the enterprise reality. The models of business process directly influence the construction of information systems [12].

CIMOSA constitutes one of the main efforts in the direction to provide an architecture, to modeling, analysis and design of enterprise systems. It is composed of three main components: Integration Infrastructure; Life Cycle of the enterprise System; and enterprise Modeling Structure. Makes possible the attainment of an integrated enterprise model, which captures and structures the essential characteristics of the enterprise beyond supplying conditions to define an infrastructure which supports the integration of the enterprise operations and, defines constructors for the principle of the particularization, where it builds a generic model or reference model which can be customized in accordance with a specific enterprise $[1,13]$.

The unified modeling Language (UML) contains notations and rules to express oriented objects models [14-15]. But it does not define how the work must be done, that is, it does not possess a development process. Larman [16], based on the best practical of development process of oriented objects systems and UML models, created the Process and Models Recommended (PMR), which will be used together with CIMOSA as follow. 


\section{MODELING PROPOSAL}

Modeling an extended enterprise requires the creation of business process models correspondent to the sub-nets of different enterprise units. To implement such cooperation and to absorb the fast changes are the challenges of the dynamic models that must allow different enterprise parts to be integrated. The availability of these models can significantly increase the operation understanding of an enterprise and improve its coordination and management [6].

CIMOSA establishes that the modeling process "Figure 1." initiates with the Requirements Definition Model (RDM), where it is necessary to find the keys areas or Domains (DMi) of the enterprise, and after established the Domain Processes (DPi) of each DMi of the enterprise. For each DPi it is defined the Enterprise Activities (EAi), that are defined by Objects View (OVi).

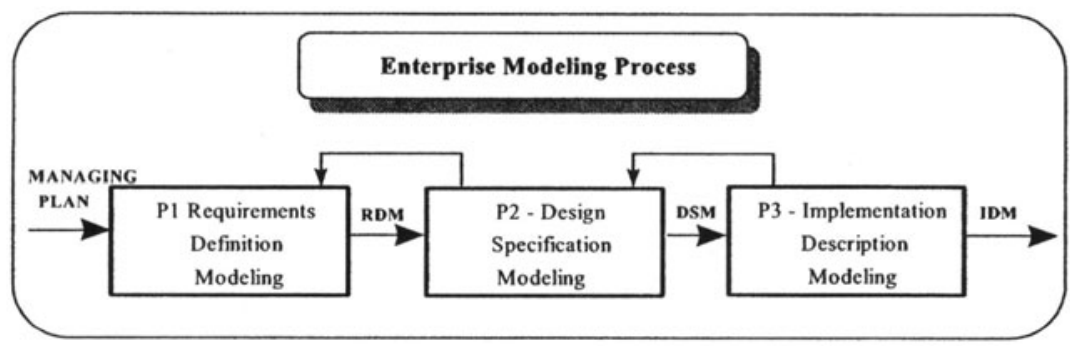

Figure 1. Main Step of the CIMOSA Process Modeling by Vernadat [1]

The modeling process considered by Larman Process and Models Recommended (PMR), also establishes 3 stages, represented in the "Figure 2." to follow:

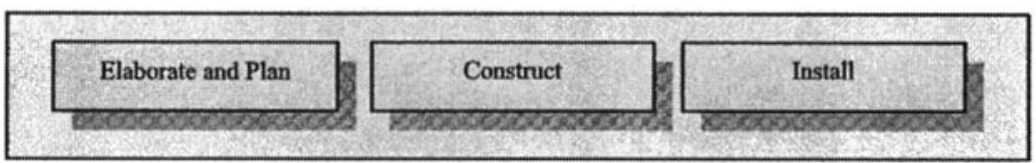

Figure 2. Steps Development in Mcro Lvel by Larman [16]

During the modeling process, in first CIMOSA stage (RDM), domain process is equivalent to the use cases of UML of PMR. Each item of CIMOSA model is represented in written form in explanatory template and it is detailed throughout the modeling process.

In the second phase of the modeling CIMOSA (PMS) the templates are reviewed and detailed. In this phase the PMR, Each cycle treats a relatively small set of requirements, and the system incrementally grows, whenever each cycle is completed. The main used diagrams are: Use Case Diagrams that represent the main EAi; Class Diagram; and Sequence Diagrams.

The third phase, is implementation description Modeling of (IDM) CIMOSA and the Install UML stage are equivalents, therefore they define tests, installation, training and other stages of system release. The model of the information system uses all pieces of information raised in the enterprise model. It has a generic character, and doing so, it is considered to be adaptable to the enterprise of different acting areas. 


\section{FINAL CONSIDERATIONS}

The new organizational paradigms impose an accelerated rhythm of adaptation in order to make the enterprises to get competitive advantages, characterized by the continuous search of the new: markets, products, business partners and technologies. The agile enterprise and the extended enterprise represent this dynamics of the markets.

The modeling based on business processes, supported by techniques of great capacity of expression as CIMOSA and UML, aims to reduce the distance among the implantation of ERP systems in dynamic and complex organizations and also to make possible its continued maintenance.

\section{REFERENCES}

1. F.B. Vernadat, Enterprise Modeling and Integration, Principles and Applications (Chapman \& Hall: Londres, 1996).

2. F.G. Goethals, M. Snoeck, W. Lemahieu, and J. Vandenbulcke, Management and enterprise architecture click: The FAD (E) E framework, Information Systems Frontiers. Volume 8, pp.67-79, (2006).

3. R.R. Campos and E.W. Cazarini, Aspects of installation technician in developed integrated systems management of under the model of free software: perspective of use in the small company (XIII Simpep, Brazil, 2006).

4. A.L. Azevedo, The emergency of virtual enterprise and the requirements for information systems, Gestão e Produção. Volume 7, Number 3, (2000).

5. J.L. Zhao, M. Tanniru, and L.J. Zhang, Services computing as the foundation of enterprise agility: Overview of recent advances and introduction to the special issue, Information Systems Frontiers. Volume 9, pp.1-8, (2007).

6. A. Kuczynski, D. Stokic, and U. Kirchhoff, Set-up and maintenance of ontologies for innovation support in extended enterprises, International Journal of Advanced Manufacturing Technology. Volume 29, pp.398-407, (2006).

7. C. Møller, ERP II: a conceptual framework for next-generation enterprise systems? Journal of Enterprise Information Management. Volume 18, pp.483-497, (2005).

8. J-P. Smets-Solanes and R.A. Carvalho, An abstract model for an open source ERP system: the ERP5 proposal (Enegep, Brazil, 2005).

9. S.V. Grabskia and S.A. Leechb, Complementary controls and ERP implementation success, Inter. J. Accounting Inf. Systems. Volume 8, pp.1-72, (2007).

10. M. Daneva and R.J. Wieringa, A requirements engineering framework for crossorganizational ERP systems, Requirements Engineering. Volume 11, pp.194-204, (2006).

11. F.P.C. Silva and N.A. Pereira, Modeling of processes business in the ERPs implementation in PMEs national, Produção. Volume 16, Number 2, pp.341-352, (2006).

12. L.R. Santos, S.V. Silva, and R. Campos, Usage of enterprise modeling processes and information systems design to forecast demand (Confenis, Áustria, 2006).

13. F.B. Vernadat, Enterprise Modeling: Objectives, constructs \& ontologies, Tutorial held at the EMOI-CAISE Workshop (Riga, Latvia, 2004).

14. G. Booch, J. Rumbaugh, and I. Jacobson, Unified Modeling Language User Guide (Addisson Wesley: Massachusetts, 1999).

15. H. Eriksson and M. Penker, Business Modeling with UML: business patterns at work (Wiley: Canada, 2000).

16. C. Larman, Applying UML and Patterns (Prentice Hall PTR: New York, 2004). 